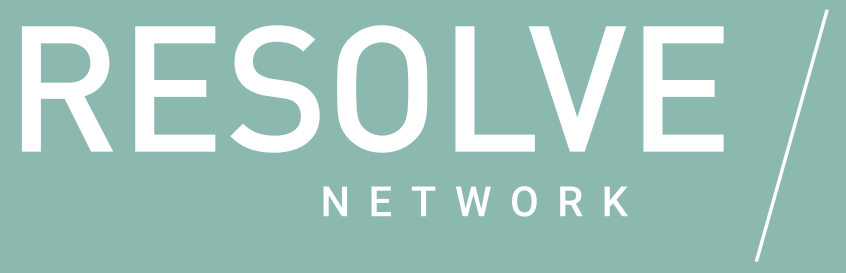

NAPOMENAO POLITICI

\author{
FEBRUAR 2021.
}

https://doi.org/ 10,37805/pn2021.5.wb

\title{
IMPERATIV PONOVNE INTEGRACIJE DJECA POVRATNICI NA ZAPADNOM BALKANU
}

\author{
ADRIAN ŠTUNI
}

\section{SERIJA O ZAPADNOM BALKANU}

\section{${ }_{9}$ Nova istraživanja i programiranja u vezi sa povratnicima iz Sirije i Iraka tek počinju da se suočavaju sa izazovom maloljetnih povratnika.}

\section{KRATKE ČINJENICE Kontekst}

$\rightarrow$ Sveukupno, u Siriji i Iraku je ostalo oko 500 stranih boraca i članova porodica sa Zapadnog Balkana.

$\rightarrow$ Navodi se da muški borci čine oko jednu trećinu lica sa Zapadnog Balkana koja su ostala u Siriji. Djeca čine oko dvije trećine,

a žene zanemarljivu manjinu.

$\rightarrow$ Trenutna mlada demografija stranaca povezanih sa sirijskim sukobom zahtjeva proaktivno djelovanje, posebno uzimanje u obzir starosti i pol, kao i odgovarajuća prilagođavanja političkih odgovora u očekivanju njihove repatrijacije.
Od 2012. godine, 1070 državljana zemalja Zapadnog Balkana otišlo je da živi i bori se na teritorijama pod kontrolom terorističkih organizacija u Siriji i Iraku. Oko 200 njih su bili maloljetni u vrijeme odlaska. Tokom godina, u sirijskom i iračkom teatru sukoba rođeno je još mnogo djece čiji su roditelji državljani Zapadnog Balkana. Do kraja 2019. godine, oko 485 osoba se vratilo kući, što Zapadni Balkan čini regionom sa najvećom koncentracijom povratnika iz Sirije i Iraka u Evropi. ${ }^{1}$ Još stotine, uglavnom maloljetnika, ostaju zarobljeni u nesigurnim uslovima u Siriji, sa neizvjesnim izgledima

1 NAPOMENA: Za više podataka i detaljnu procjenu trenutnog stanja kontingenta stranih boraca i članova njihovih porodica na Zapadnom Balkanu, pogledajte: Adrian Štuni, "Strani borci i domaći džihadisti Zapadnog Balkana: Trendovi i posljedice, borba protiv terorizma", CTC Sentinel 12, br. 7 (13. avgust 2019. godine):18-24, https://ctc. usma.edu/western-balkans-foreign-fighters-homegrown-jihadis- t rends-implications/. 
za repatrijaciju. ${ }^{2}$ Brojne zemlje se bore sa tim šta da rade sa državljanima koji su otišli da žive i bore se u takozvanom „kalifatu“ Islamske države (IS). Međutim, iskustvo i razumijevanje onoga što omogućava efikasno angažovanje u pogledu povratnika iz Sirije, naročito djece povratnika, u ranoj je fazi. Ova napomena o politici pruža preporuke o načinima za pristupanje rehabilitaciji i reintegraciji $(R \& R)$ djece povratnika na Zapadni Balkan, kombinujući novonastale dobre prakse sa vodećim principima konvencija, sporazuma i protokola usmjerenih na prava djece.

\section{Kampovi za pritvor, početna repatrijacija i tekući izazovi}

Nakon sloma fizičkog „kalifata“ IS-a, desetine hiljada boraca koji su se predali i članova njihovih porodica se nalaze u prenatrpanim kurdskim pritvorskim objektima i kampovima interno raseljenih lica (IRL). Kamp Al Hol, u kom se nalazi najviše članova porodica boraca IS-a, prihvatio je 68.823 lica u avgustu 2019. godine ${ }^{3}$ - prvobitno je dizajniran za smještaj oko sedam puta manje osoba. ${ }^{4}$ U nedavnom izvještaju Savjeta Ujedinjenih nacija za ljudska prava, uslovi u Al Holu opisani su kao „žalosni i nehumani“. ${ }^{5}$ Od ukupnog broja ljudi smještenih u Al Holu, oko 7.000 su strani maloljetnici, a oko 3.000 su žene strankinje iz oko 50 zemalja $^{6}$ - uključujući stotine sa Zapadnog Balkana.

Sveukupno, u Siriji i Iraku je ostalo oko 500 stranih boraca i članova porodica sa Zapadnog Balkana. Navodi se da muški borci čine oko jednu trećinu ovog kontingenta sa Zapadnog Balkana, dok djeca čine oko dvije trećine, a žene zanemarljivu manjinu. Mnogi od ovih boraca i članova porodica žele da se vrate u svoje matične zemlje.

Dosad mnoge vlade nijesu bile voljne da repatriraju svoje građane zbog tehničkih i pravnih poteškoća, političkih stavova i bezbjednosnih razloga. ${ }^{7}$ Evropske zemlje poput Francuske, Njemačke, Holandije, Norveške i Belgije odlučile su da repatriraju, gotovo isključivo, samo nekoliko djece bez roditelja, svojih državljana koji su se pridružili IS-u. Kosovo je dosad jedna od rijetkih zemalja u Evropi koja je prihvatila grupnu repatrijaciju 110 državljana, od kojih su preko dvije trećine (74) djeca, uključujući i one koji su rođeni u Siriji i Iraku, a čiji je bar jedan roditelj državljanin Kosova. ${ }^{8}$ Krajem decembra 2019. godine, Bosna i Hercegovina je takođe repatrirala 25 svojih građana, od kojih 12 djece. ${ }^{9}$ lako 25 repatriranih bosanskih državljana čine samo jednu desetinu ukupnog broja bosanskih

2 Ibid.

3 Sirijska Arapska Republika: Sjeveroistočna Sirija: Kamp Al Hol“, OCHA, 1. avgust 2019. godine, https://reliefweb.int/sites/ reliefweb.int/files/resources/Al-Hol-Snapshot-SitRip-040819.pdf.

4 Kirtana Anamaneni, „Djeca ISIS-a nailaze na otpor prilikom povratka kući u Evropu“, Njujork tajms, 15. avgust 2019. godine, https://www.nytimes.com/2019/08/15/world/europe/isis-children-belgium.html.

5 Istražna komisija Ujedinjenih nacija o Siriji, Eskalirajuće nasilje i talasi raseljavanja i dalje muče civile tokom osme godine sirijskog sukoba: (Ženeva: Savjet Ujedinjenih nacija za ljudska prava, 2019. godine), https://www.ohchr.org/EN/ HRBodies/ HRC/Pages/NewsDetail.aspx?NewsID=24972\&LangID=E.

6 Ibid.

7 Majkl Birnbaum, „Mjesecima nakon pada ISIS-a, Evropa je učinila malo da vrati svoje borce“, Vašington post, 20. jun 2019. godine, https://www.washingtonpost.com/world/europe/after-caliphate-collapsed-europe-has-done-little-to-take-backthose-who-joined-isis/2019/06/20/4bab9cc2-8bc4-11e9-b6f4-033356502dce story.html.

8 Fatos Bitići, „Kosovo vraća borce, porodice džihadista iz Sirije“, Rojters, 20. april 2019. godine, https://www.reuters.com/ article/us-kosovo-syria/kosovo-brings-back-fighters-families-of-jihadists-from-syria-idUSKCN1RW003.

9 „Vlasti kažu da je 25 Bosanaca poslato kući iz kampova u Siriji“, AP njuz, 19. decembar 2019. godine, https://apnews. com/850b5ffb b045c65f1dfbbce52c9ff182. 
državljana u sirijskim kampovima - prema zvaničnim izvorima procjenjuje se da ih je $260^{10}$ njihova repatrijacija je od velike važnosti. Spremnost Kosova i Bosne, dvije inače male zemlje sa skromnim resursima, da omoguće povratak svojih građana, naročito djece, signali su da može da se smogne politička volja za rješavanje ovog mučnog pitanja na Zapadnom Balkanu, uprkos brojnim objektivnim poteškoćama.

Ipak, druge zemlje u regionu su u velikoj mjeri pokazale nevoljnost, odnosno nedostatak planova za povratak svojih državljana. Nijedna druga zemlja Zapadnog Balkana dosad nije objavila nijedan plan ili vremenski raspored za repatrijaciju. Jasna strategija za rješavanje ovog složenog izazova i dalje je nedostižna. Kurdski privremeni kampovi i zatvori neće omogućiti dugoročno rješenje ovog gorućeg pitanja, naročito s obzirom na to da u kontingentu stranaca koji se tamo nalaze dominiraju ranjivi maloljetnici, izloženi patnji i pogodni za radikalizaciju. ${ }^{11}$ Trenutna mlada demografija stranaca povezanih sa sirijskim sukobom zahtjeva proaktivno djelovanje, posebno uzimanje u obzir starosti i pol, kao i odgovarajuća prilagođavanja političkih odgovora u očekivanju njihove repatrijacije. To je naročito slučaj na Zapadnom Balkanu, koji ima veći broj povratnika ili onih koji će vjerovatno biti repatrirani, a mnogo manje u pogledu resursa, kapaciteta i stručnosti koji su na raspolaganju za efikasno bavljenje njima, u poređenju sa većinom drugih evropskih država.

\section{Preporuke}

Nova istraživanja i programiranja u vezi sa povratnicima iz Sirije i Iraka tek počinju da se suočavaju sa izazovom maloljetnih povratnika. Prilagođeni programi sa osvrtom na faktore starosti i pola i dalje su rijetki. lako je iskustvo po pitanju efikasnog angažovanja sa djecom povratnicima iz Sirije i Iraka u ranoj fazi, postepeno se pojavljuju početne dobre prakse u vezi sa R\&R naporima. ${ }^{12}$ Korisna istraživanja i dobre prakse iz rehabilitacionog rada sa djecom-vojnicima ili maloljetnicima izloženim ratnim traumama takođe mogu da pruže efikasne političke odgovore za rješavanje $R \& R$ pitanja djece povratnika na Zapadnom Balkanu, u skladu sa vodećim konvencijama, sporazumima i protokolima u kojima se definišu prava djece.

\section{Proaktivno, transparentno i inkluzivno kreiranje politike}

$\rightarrow$ Usvojiti proaktivni i inkluzivni pristup na nivou više agencija, obavezujući se na dugoročnu R\&R strategiju. Državni organi treba da proaktivno investiraju u partnerstva sa više agencija i programe koji su fleksibilni, adekvatno finansirani i inkluzivni, uz integrisanje građanskog društva u ranoj fazi procesa. Međunarodni donatori i specijalizovane agencije treba da obezbijede dodatna finansijska sredstva i napore za razvoj kapaciteta za rješavanje pitanja nedostatka resursa i stručnosti. Sa preko 400 djece i 150 žena repatriranih iz Sirije i Iraka ${ }^{13}$ do danas, napori Kazahstana mogu pružiti uvid u takav pristup. Do kraja 2019. godine,

10 „Bosna: Građani koji su se borili za IS u Siriji mogu da se vrate“, AP njuz, 11. novembar 2019. godine, https://apnews. com/818776caf4a44 b6f97d8eb5c285ace00.

11 Savjet Ujedinjenih nacija za ljudska prava, Izvještaj Nezavisne međunarodne istražne komisije o Sirijskoj Arapskoj Republici, A/HRC/42/51 (Njujork: Generalna skupština Ujedinjenih nacija, 2019. godine), https://www.securitycouncilreport.org/atf/ cf/\%7B65BFCF9B-6D27-4E9C-8CD3-CF6E4FF96FF9\%7D/a hrc 42 51.pdf.

12 Više detalja potražite $u$ „Predloženo dodatno štivo, po temama“ na kraju ove Napomene o politici.

13 „Operacija Zhusan: 595 Kazahstanaca repatrirano iz Sirije“, Međunarodna novinska agencija Kazinform, 6. februar 2020. godine, https://www.inform.kz/en/zhusan-operation-595-kazakhstanis-repatriated-from-syria a3611674. 
osnovao je 17 regionalnih prihvatnih i rehabilitacionih centara ${ }^{14}$ za smještaj povratnika na neograničeni vremenski period, u zavisnosti od individualnih potreba i napretka po pitanju deradikalizacije. ${ }^{15}$ Centri ne pružaju samo usluge smještaja, već i medicinsko i psihološko liječenje, obrazovanje, pravnu pomoć, umjetničku terapiju i osposobljavanje za rad. ${ }^{16}$ Nastavni plan i program je osmišljen uz učešće grupe NVO-a, dok socijalni radnici i vladine agencije koordiniraju implementaciju programa. ${ }^{17}$

$\rightarrow$ Izraditi protokole angažovanja, prilagođene maloljetnim povratnicima, učiniti ih javnim i decentralizovati proces implementacije, gdje god je to moguće. Pristup angažovanja, osmišljen na osnovu posebnih potreba maloljetnika vjerovatno će omogućiti efikasniji psihosocijalni oporavak i ubrzanu reintegraciju djece povratnika. Objavljivanje ovih smjernica omogućilo bi dodatnu transparentnost, odgovornost i podršku procesu. Decentralizovani pristup implementacije, koji vode lokalne vlasti i NVO-i, vjerovatno će podstaći povećano angažovanje i vlasništvo nad R\&R procesom na nivou zajednice. Uprkos tome što je početkom 2020. godine repatrirala samo 17 maloljetnika ${ }^{18}$, uglavnom djece bez roditelja, Francuska je izradila i objavila detaljne smjernice i modalitete za tretman repatriranih francuskih i stranih maloljetnika, koji su se početkom 2017. godine vratili iz Sirije i Iraka. ${ }^{19} \mathrm{U}$ strateškom dokumentu se naglašava vodeća uloga lokalnih vlasti i regionalnih kancelarija i on uključuje šemu za koordinaciju i razmjenu informacija između agencija odgovornih za njegovu implementaciju.

$\rightarrow$ Okvir i pristup R\&R djece povratnika kroz objektiv obrazovanja. Zbog razloga nacionalne bezbjednosti, neki aspekti repatrijacije i R\&R povratnika, naročito odraslih, neizbježno su povezani sa sprovođenjem zakona i krivičnim pravom. Međutim, za djecu su obrazovanje i stručno osposobljavanje neki od najvažnijih R\&R aspekata, koji nude put u novu budućnost, kao u programima reintegracije za djecu-vojnike. ${ }^{20} \mathrm{~S}$ obzirom na to, odgovarajuća ministarstva obrazovanja svake zemlje Zapadnog Balkana, na primjer, mogu biti u boljem položaju i pogodnija od ministarstava unutrašnjih poslova kada je riječ o

14 Stevan Vajn, „Rehabilitacija žena i djece povratnika Islamske države u Kazahstanu“, Džast sikjuriti, 12. decembar 2019. godine, https://www.justsecurity.org/67694/rehabilitating-the-islamic-states-women-and-children-returnees-in-kazakhstan/.

„39 porodica vraćeno iz Sirije u Kazahstan“, Kazahstan tudej, 18. novembar 2019. godine, https://www.kt.kz/ eng/ international affair/39 families have been returned back from syria to kazakhstan 1153667282.html

16 Ksenia Bondal, „Kazahstan rehabilituje djecu nedavno vraćenu iz Sirije, Iraka“, Karavan-saraj, 8. januar 2019. godine, http:// central.asia-ews.com/en GB/articles/cnmi ca/features/2019/01/08/feature-01.

17 Endru E. Krejmer, „Kazahstan oprezno dočekuje žene koje se vraćaju iz Islamske države“, Njujork tajms, 10. avgust 2019. godine, https://www.nytimes.com/2019/08/10/world/europe/kazakhstan-women-islamic-state-deradicalization.html.

Benžamin Sportuš i Šarl Deluermoz, „Enfants de jihadistes: 'Nous en avons rapatrié 17' en France, annonce Le Drian sur RTL“, RTL, 2. februar 2020. godine, https://www.rtl.fr/actu/politique/ enfants-de-jihadistes-nous-en-avons-rapatrie-17-enfrance-annonce-le-drian-sur-rtl-7800014980.

Kancelarija premijera vlade Francuske, Instruction relative à la prise en charge des mineurs à leur retour de zone irakosyrienne, Dopis br. 5923/SG (Pariz: Vlada Francuske, mart 2017. godine), http://circulaires.legifrance.gouv.fr/pdf/2017/03/ cir 41965.pdf.

20 Kancelarija specijalnog predstavnika generalnog sekretara za djecu i oružane sukobe, Reintegracija nekadašnje djecevojnika (Njujork: Sekretarijat Ujedinjenih nacija, 2018. godine), https://childrenandarmedconflict.un.org/wp-content/ uploads/2018/09/Reintergration-brochure-layout.pdf; Skender Perteši i Ramadan Ilazi, Otkrivanje odgovora Kosova na povratnike iz ratnih zona u Siriji i Iraku (Priština: Kosovski centar za studije bezbjednosti, 2020. godine), http://www.qkss. org/repository/docs/violent-extremism-eng 978757.pdf. 
vođenju i koordinaciji rehabilitacije djece uključene u nasilni ekstremistički sukob. Izbor ministarstva je važan jer što odražava i saopštava javnosti sveukupan način razmišljanja vlade po pitanju angažovanja. U Kazahstanu je vlada odlučila da Ministarstvo obrazovanja bude zaduženo za program R\&R. Njihovo iskustvo može pružiti neke korisne uvide u tom pogledu. ${ }^{21}$

\section{Zaštititi dijete i pružiti mu podršku}

$\rightarrow$ Podržati mjere kojima se daje prioritet najboljem interesu djece povratnika i najbržoj razumnoj R\&R u glavne društvene tokove. Pravosudne institucije treba da djeluju u skladu sa međunarodnim pravom ivažećim standardima maloljetničkog pravosuđa. U slučajevima kada je krivično gonjenje djece mlađe od 18 godina zagarantovano, u skladu sa Konvencijom o pravima djeteta treba razmotriti alternative pritvoru i lišavanju slobode. ${ }^{22}$ Rezolucija Generalne skupštine 70/291 o Pregledu Globalne strategije Ujedinjenih Nacija za borbu protiv terorizma bavi se ovim konkretnim pitanjem i treba je konsultovati prilikom izrade odgovarajućih pravnih mehanizama. ${ }^{23}$

$\rightarrow$ Izvršiti procjene rizika i potreba, u cilju procjene mentalnog blagostanja i nivoa traume djece povratnika prije pružanja psihosocijalne podrške, prilagođene individualnim potrebama. Djeca povratnici bila su izložena djelima ekstremnog nasilja i, u nekim slučajevima, možda su pretrpjela ekstremno nasilje iz prve ruke. U drugim slučajevima, ona su možda učestvovala u izvršenju nasilnih ekstremističkih djela. Agencije nadležne za javno zdravlje treba da sprovode temeljne i periodične procjene, kako bi zasebno procijenile svaki slučaj. ${ }^{24}$ Kako su neka starija djeca povratnici vjerovatno bila podvrgnuta nasilnoj ekstremističkoj indoktrinaciji i obuci dok su bila u Siriji i Iraku, vlasti treba da procjene njihov potencijalni rizik i pruže specijalizovanu njegu za rješavanje njihove indoktrinacije i obuke prije njihove tranzicije u javno obrazovno okruženje. Krajem aprila 2019. godine, Kosovo je repatriralo 74 maloljetnika iz Sirije. Do septembra, sva djeca školskog uzrasta među tim povratnicima bila su

spremna za polazak u školu. ${ }^{25} \mathrm{~S}$ obzirom na to da je njihova efikasna inkluzija u glavne društvene tokove krajnji cilj napora za reintegraciju, upis djece povratnika je pozitivan korak. Ipak, nejasno je koliko prilagođenu psihološku i akademsku podršku su dobili prije upisa u državne škole nekoliko mjeseci nakon povratka.

sionalinterest/pages/crc.aspx; Kancelarija Ujedinjenih nacija za borbu protiv terorizma (UNCCT), Djeca pogođena fenomenom stranih boraca: Osiguravanje pristupa zasnovanog na pravima djeteta (Njujork: UNCCT, 2019), https://www. un.org/counterterrorism/ctitf/sites/www.un.org.counterterrorism.ctitf/files/ftf handbook web reduced.pdf.

eralna skupština Ujedinjenih nacija, 70. zasjedanje, „Rezolucija 70/291 [Pregled Globalne strategije Ujedinjenih Nacija za borbu protiv terorizma]“ (A/RES/70/291), 1. jul 2016. godine, https://www.un.org/sc/ctc/news/ document/a-res-70-291-the-united-nations-global-counter-terrorism-strategy-review/.

Organizacija za evropsku bezbjednost i saradnju (OEBS), Rehabilitacija i reintegracija van pritvora u sprečavanju i suzbijanju nasilnog ekstremizma i radikalizacije koji vode ka terorizmu Vodič za kreatore politike i praktičare u Jugoistočnoj Evropi (Beč, OEBS, 2020. godine), https://www.osce.org/secretariat/444838?download=true.

25 Taulant Ćenaj, „Fëmijët e Kthyer Nga Siria, Sërish Në Shkolla“, Radio Evropa e Lirë, 27. avgust 2019. godine, https://www. evropaelire. org/a/femijet-e-kthyer-nga-siria-shkollim-/30130050.html. 
$\rightarrow$ Sprovesti psihometrijske testove za procjenu intelektualnog razvoja djece povratnika, kako bi se osigurao adekvatan smještaj u obrazovni sistem i po potrebi pružila akademska pomoć. Ovi napori će vjerovatno biti efikasniji ako djeca ne budu institucionalizovana, već dobiju akademsku obuku i psihološku pomoć kod kuće, eventualno od strane mobilnih timova stručnjaka. To može pomoći da se izbjegne osjećaj neadekvatnosti, stigme i potencijalne marginalizacije, sve dok povratnicima ne bude prijatnije u novom socijalnom okruženju. Na primjer, u Francuskoj, nakon što tužilac i sudija za maloljetnike procjene slučaj bilo kog djeteta povratnika, maloljetnici dobijaju somatski i psihološki pregled, pod brigom socijalnih službi. Odluke o školovanju donose se uz konsultacije između akademskog direktora nacionalnih obrazovnih službi, obrazovnih institucija i praktičara koji implementiraju i nadgledaju R\&R napore. ${ }^{26}$

\section{Zaključak}

Na kraju, uspješna rehabilitacija i reintegracija djece povratnika će zahtijevati usvajanje holističke strategije psihosocijalne podrške, koja će se baviti svim aspektima njihove socijalne interakcije i reintegracije u kući, školi i zajednici. Kao takav, na napredak svakog djeteta povratnika na R\&R putu snažno će uticati pogled na svijet i stav roditelja i rođaka koji žive sa njima. Stoga, programi treba da pruže širu podršku za rješavanje pitanja radikalizacije nasilja i traume u cijeloj porodici. Takođe, nastavnici i drugi praktičari uključeni u proces obrazovanja i rehabilitacije djece povratnika treba da prođu obuku o svijesti o traumi i dobiju informacije o procesu radikalizacije, uključujući i kako odgovoriti na znake zabrinjavajućeg ponašanja i gdje zatražiti dodatnu podršku. Sa poboljšanim znanjem, vještinama i alatima za rješavanje zabrinutosti zajednica koje primaju povratnike i stvarnosti iskustava povratnika, zemlje Zapadnog Balkana mogu da omoguće laganiju i sigurniju tranziciju povratnika u glavne društvene tokove.

26 Kancelarija premijera vlade Francuske, Instruction relative à la prise en charge des mineurs à leur retour de zone irakosyrienne, Dopis br. 5923/SG. 


\section{Predložena dodatna literatura, po temama}

\section{O regrutovanju i eksploataciji djece od strane terorista}

Mia Blum sa Džonom Horganom. Lako naoružanje: Djeca i terorizam. Itaka, Njujork: Kornel juniverziti pres, 2019. godine.

Kancelarija Ujedinjenih nacija za drogu i kriminal (UNODC). Priručnik o djeci regrutovanoj i eksploatisanoj od strane terorističkih i nasilnih ekstremističkih grupa: Uloga pravosudnog sistema. Beč: UNODC, 2017. godine. https://www.unodc.org/documents/justice-and-prison-reform/Child-Victims/Handbook on Children Recruited_and Exploited by Terrorist and Violent Extremist Groups the Role of the Justice System.E.pdf.

\section{O djeci povezanoj sa terorističkim organizacijama u Siriji i Iraku}

Džoana Kuk i Džina Vale. „Od Daeša do 'dijaspore' II: Izazovi koje predstavljaju žene i maloljetnici nakon pada kalifata". CTC Sentinel 12, br. 6 (jul 2019. godine): 30-45. (jul 2019. godine) https://ctc.usma. edu/daesh-diaspora-challenges-posed-women-minors-fall-caliphate/.

\section{O rehabilitaciji i reintegraciji djece}

Mejnes, Mareje, Merel Molenkamp, Omar Ramadan i Magnus Ranstorp. RAN priručnik: Odgovori povratnicima: Inostrani teroristički borci i njihove porodice. Amsterdam: Mreža za osvješćivanje o radikalizaciji (RAN), Centar izvrsnosti, 2017. godine. https://ec.europa.eu/home-affairs/sites/ homeaffairs/files/ ran br a4 m10 en.pdf.

Globalni forum za borbu protiv terorizma (GCTF). Dobre prakse o rješavanju izazova povratničkih porodica stranih terorističkih boraca. GCTF, 2018. https://www.thegctf.org/Portals/1/Docu- ments/ Framework\%20Documents/2018/GCTF-Good-Practices-on-Returning-Families-of-FTFs ENG. pdf?ver=2018-09-25-101427-323.

Ujedinjene nacije. Ključni principi za zaštitu, repatrijaciju, krivično gonjenje, rehabilitaciju i reintegraciju žena i djece povezanih sa terorističkim grupama koje su na listi Ujedinjenih nacija. Ujedinjene nacije, 2019. https://www.un.org/counterterrorism/ctitf/sites/www.un.org.counterterrorism. ctitf/files/Key\%20 Principles\%20-\%20April\%202019 0.pdf.

Kancelarija Ujedinjenih nacija za borbu protiv terorizma (UNCCT). Djeca pogođena fenomenom stranih boraca: Osiguravanje pristupa zasnovanog na pravima djeteta. Njujork: UNCCT, 2019. godine. https://www.un.org/counter- terrorism/ctitf/sites/www.un.org.counterterrorism.ctitf/files/ftf handbook web reduced.pdf

Kancelarija Ujedinjenih nacija za drogu i kriminal (UNODC). Mapa puta za tretman djece povezane sa terorističkim i nasilnim ekstremističkim grupama. Beč: UNODC, 2019. godine. https://indd.adobe. com/ view/61793921-8dc6-4fc2-9e46-b27c6390fff2.

van der Hejde, Lisbet i Jip Genen. Djeca kalifata: Mladi povratnici iz IS-a i izazov reintegracije. Hag: Međunarodni centar za borbu protiv terorizma - Hag, 2017. godine. https://icct. nl/wp-content/ uploads/2017/08/ICCT-vanderHeide-Geenen-Children-of-the-Caliphate-2.pdf.

\section{O izazovima sa kojima se suočavaju praktičari koji rade sa djecom povratnicima}

Mreža za osvješćivanje o radikalizaciji (RAN). Djeca povratnici iz zona sukoba. Amsterdam: RAN centar izvrsnosti, 2016. godine. https://ec.europa.eu/home-affairs/sites/homeaffairs/files/what-we-do/ networks/radicalisation awareness network/ran-papers/docs/issue paper child returnees from conflict zones 112016 en.pdf. 


\section{Izvori}

„39 porodica vraćeno iz Sirije u Kazahstan“. Kazahstan tudej, 18. novembar 2019. godine. https://www.kt.kz/eng/ international affair/39 families have been returned back from syria to kazakhstan 1153667282.html.

Anamaneni, Kirtana. „Djeca ISIS-a nailaze na otpor prilikom povratka kući u Evropu“. Njujork tajms, 15. avgust 2019. https://www. nytimes.com/2019/08/15/world/europe/isis-children-belgium.html.

„Vlasti kažu da je 25 Bosanaca poslato kući iz kampova u Siriji“. AP njuz, 19. decembar 2019. https://apnews.com/850b5ffbb045 c65f1dfbbce52c9ff182.

Birnbaum, Majkl. „Mjesecima nakon pada ISIS-a, Evropa je učinila malo da vrati svoje borce“. Vašington Post, 20. jun 2019. https:// www.washingtonpost.com/world/europe/after-caliphate-collapsed-europe-has-done-little-to-take-back- those-who-joinedisis/2019/06/20/4bab9cc2-8bc4-11e9-b6f4-033356502dce story.html.

Bondal, Ksenia. „Kazahstan rehabilituje djecu nedavno vraćenu iz Sirije, Iraka“. Karavan-saraj, 8. januar 2019. http:// central.asiaews.com/en GB/articles/cnmi ca/features/2019/01/08/feature-01.

„Bosna: Građani koji su se borili za IS u Siriji mogu da se vrate“. AP njuz, 11. novembar 2019. https://apnews.com/818776caf4a44b6f 97d8eb5c285ace00.

Bitići, Fatos. „Kosovo vraća borce, porodice džihadista iz Sirije“. Rojters, 20. april 2019. https://www.reuters.com/article/ us-kosovo-syria/kosovo-brings-back-fighters-families-of-jihadists-from-syria-idUSKCN1RW003.

Krejmer, Endru E, „Kazahstan oprezno dočekuje žene koje se vraćaju iz Islamske države“. Njujork tajms, 10. avgust 2019. https:// www.nytimes.com/2019/08/10/world/europe/kazakhstan-women-islamic-state-deradicalization.html.

Kancelarija specijalnog predstavnika generalnog sekretara za djecu i oružane sukobe. Reintegracija nekadašnje djece-vojnika. Njujork: Sekretarijat Ujedinjenih nacija, 2018. godine. https://childrenandarmedconflict.un.org/wp-content/uploads/2018/09/ Reintergration-brochure-layout.pdf.

Organizacija za evropsku bezbjednost i saradnju (OEBS). Rehabilitacija i reintegracija van pritvora u sprečavanju i suzbijanju nasilnog ekstremizma i radikalizacije koji vode ka terorizmu Vodič za kreatore politike i praktičare u Jugoistočnoj Evropi. Beč, OEBS, 2020. https://www.osce.org/secretariat/444838?download=true.

Perteši, Skender i Ramadan Ilazi. Otkrivanje odgovora Kosova na povratnike iz ratnih zona u Siriji i Iraku. Priština: Kosovski centar za studije bezbjednosti, 2020. http://www.qkss.org/repository/docs/violent-extremism-eng 978757.pdf.

Kancelarija premijera vlade Francuske. Instruction relative à la prise en charge des mineurs à leur retour de zone irako-syrienne, Dopis br. 5923/SG. Pariz: Vlada Francuske, mart 2017. godine. http://circulaires.legifrance.gouv.fr/ pdf/2017/03/cir 41965. pdf.

Ćenaj, Taulant. „Fëmijët e Kthyer Nga Siria, Sërish Në Shkolla“. Radio Evropa e Lirë, 27. avgust 2019. https://www.evropaelire. org/a/femijet-e-kthyer-nga-siria-shkollim-/30130050.html.

Štuni, Adrian. ,Straniborciidomaći džihadistiZapadnog Balkana:Trendoviiposljedice, borba protivterorizma“. CTCSentine/12, br. 7(13. avgust2019.godine):18-24. https://ctc.usma.edu/western-balkans-foreign-fighters-homegrown-jihadis-trends-implications/.

Benžamin Sportuš i Šarl Deluermoz. „Enfants de jihadistes: 'Nous en avons rapatrié 17' en France, annonce Le Drian sur RTL“. RTL, 2. februar 2020. https://www.rtl.fr/actu/politique/enfants-de-jihadistes-nous-en-avons-rapatrie-17-en-france- annonce-ledrian-sur-rtl-7800014980.

„Sirijska Arapska Republika: Sjeveroistočna Sirija: Kamp Al Hol“. OCHA, 1. avgust 2019. https://reliefweb.int/sites/reliefweb.int/ files/ resources/Al-Hol-Snapshot-SitRip-040819.pdf. 
Istražna komisija Ujedinjenih nacija o Siriji. Eskalirajuće nasilje i talasi raseljavanja i dalje muče civile tokom osme godine sirijskog sukoba. Ženeva: Savjet Ujedinjenih nacija za ljudska prava, 2019. godine. https://www.ohchr.org/EN/HRBodies/ HRC/Pages/ NewsDetail.aspx?News ID=24972\&Lang|D=E.

Generalna skupština Ujedinjenih nacija. Konvencija o pravima djeteta. Njujork: Generalna skupština Ujedinjenih nacija, 1989. godine. https://www.ohchr.org/en/professionalinterest/pages/crc.aspx.

- - , 70. zasjedanje. „Rezolucija 70/291 [Pregled Globalne strategije Ujedinjenih Nacija za borbu protiv terorizma]“ (A/ RES/70/291), 1. jul 2016. godine. https://www.un.org/sc/ctc/news/document/a-res-70-291-the-united-nations-globalcounter-terrorism-strategy-review/.

Savjet Ujedinjenih nacija za ljudska prava. Izvještaj Nezavisne međunarodne istražne komisije o Sirijskoj Arapskoj Republici, A/ HRC/42/51. Njujork: Generalna skupština Ujedinjenih nacija, 2019. godine. https://www.securitycouncilreport.org/atf/ cf/\%7B65BFCF9B- 6D27-4E9C-8CD3-CF6E4FF96FF9\%7D/a hrc 42 51.pdf.

Kancelarija Ujedinjenih nacija za borbu protiv terorizma (UNCCT). Djeca pogođena fenomenom stranih boraca: Osiguravanje pristupa zasnovanog na pravima djeteta. Njujork: UNCCT, 2019. godine. https://www.un.org/counterterrorism/ctitf/sites/ www.un.org.counterterrorism.ctitf/files/ftf handbook web reduced.pdf.

Vajn, Stevan. „Rehabilitacija žena i djece povratnika Islamske države u Kazahstanu“. Džast sikjuriti, 12. decembar 2019. https:// www.justsecurity.org/67694/rehabilitating-the-islamic-states-women-and-children-returnees-in-kazakhstan/.

„Operacija Zhusan: 595 Kazahstanaca repatrirano iz Sirije“. Međunarodna novinska agencija Kazinform, 6. februar 2020. https:// www.inform.kz/en/zhusan-operation-595-kazakhstanis-repatriated-from-syria a3611674. 


\section{O napomeni}

Autor: Adrian Štuni, direktor kompanije Shtuni Consulting DOO, stručnjak je za stranu politiku, bezbjednost i strateške komunikacije sa regionalnim fokusom na Zapadni Balkan. On radi kao konsultant za agencije vlade SAD-a, akademske institucije i međunarodne organizacije u Sjedinjenim Državama, Evropi i Aziji u vezi sa temama suzbijanja nasilnog ekstremizma, protivterorizma, političkog rizika, sprečavanja strane propagande i dezinformisanja, kao i drugih transnacionalnih prijetnji.

Stavovi izraženi u ovom izdanju su lični stavovi autora. Oni ne odražavaju nužno stavove RESOLVE mreže, Američkog instituta za mir niti bilo kojeg subjekta vlade SAD.

RESOLVE MREŽA

bolje istraživanje.informisana praksa•poboljšana politika u vezi sa nasilnim ekstremizmom.

www.resolvenet.org

Y $f$ in 